ICPEAC 2003, Physica Scripta, submitted 2003

\title{
Electron attachment to uracil, thymine and cytosine
}

\author{
S. Denifl, S. Ptasinska, G.Hanel, B.Gstir, P.Scheier, M.Probst, B.Farizon ${ }^{1)}$, M.Farizon ${ }^{1)}$, S. \\ Matejcik $^{2)}$, E.Illenberger ${ }^{3)}$ and T. D. Märk ${ }^{4)}$ \\ Institut für Ionenphysik, Leopold-Franzens Universität Innsbruck, Technikerstr. 25, A-6020 \\ Innsbruck, Austria
}

\begin{abstract}
Electron attachment (EA) to uracil (U), thymine (T) and cytosine (C) was studied in the electron energy range from about 0 to $12 \mathrm{eV}$ using a high resolution crossed electron/molecule beams technique. The dominant negative ions formed via EA reactions to $\mathrm{U}, \mathrm{T}$ and $\mathrm{C}$ are $(\mathrm{U}-\mathrm{H})^{-},(\mathrm{T}-\mathrm{H})^{-}$and $(\mathrm{C}-\mathrm{H})^{-}$. The respective partial EA cross sections could be determined yielding peak values of $\sigma(1.0 \mathrm{eV})=3 \times 10^{-20} \mathrm{~m}^{2}, \quad \sigma(1.05 \mathrm{eV})=1.2 \times 10^{-19} \mathrm{~m}^{2}, \sigma$ $(1.54 \mathrm{eV})=2.3 \times 10^{-20} \mathrm{~m}^{2}$, respectively. Based on (i) a comparison of the resonance positions for the different bases and on (ii) high level ab initio calculations we can assign certain resonances to the site specific loss of hydrogen during the EA reaction. At higher electron energies, in the range between about 3 and $12 \mathrm{eV}$ we observe further product anions (e.g., for $\mathrm{U}$ the ions $\mathrm{CN}^{-}, \mathrm{OCN}^{-}$and $\left.\mathrm{C}_{3} \mathrm{OH}_{2} \mathrm{~N}^{-}\right)$, however, with significantly lower cross section values.
\end{abstract}

1) Permanent address:Institut de Physique Nucleaire de Lyon,43 boulevard du 11 Novembre 1918, F-69622 Villeurbanne, France

2) Permanent address: Department of Plasma Physics, Comenius University, SK-84248

Bratislava, Slovakia

3) Permanent address: Inst.f. Physikalische Chemie, FU Berlin, Takustr.3, D-14195,

Germany

4) Corresponding author; E-mail:Tilmann.Maerk@uibk.ac.at. Also adjunct professor at:

Department of Plasma Physics, Comenius University, SK-84248 Bratislava, Slovakia 


\section{Introduction}

Ionising radiation ( $\alpha, \beta, \mathrm{X}$ - and $\gamma$-rays) may induce genotoxic damage in cells such as single- and double-strand breaks (SSB and DSB). According to [1] the primary radiation is responsible for about one third of the mutagenic damages and about two thirds of the damages can be linked to secondary species such as electrons and radicals formed in the interaction of the primary radiation with the radiated medium. The most abundant secondary species are electrons, which are produced with energies of up to $20 \mathrm{eV}$ and an estimated rate of about $5 \mathrm{x}$ $10^{4}$ electrons per MeV primary energy deposited [2,3]. It is thought that in the course of successive inelastic collisions within the medium they are thermalized within $10^{-12} \mathrm{~s}$ before they reach some stage of solvation. Sanche and co-workers [4] demonstrated that low energy $(\sim 3-20 \mathrm{eV})$ electrons may induce SSB and DSB in supercoiled DNA deposited on a cold surface. It was argued [4] that resonances observed in this experiment are reminiscent of the resonances observed in gas phase electron attachment experiments to various components of DNA in the gas phase or in homogeneous films.

In order to distinguish between environmental effects and intrinsic molecular effects, it is important to study interactions of primary and secondary radiation (species) also with isolated nucleic acid bases. Concerning electron interaction with nucleic bases, two series of electron attachment experiments are noteworthy one involving bound electrons and one free electrons. Schermann and co-workers [5] studied charge transfer reactions between Rydberg atoms and gas phase uracil (U), thymine (T) and adenine (A) molecules. They observed dipole-bound parent negative ions (see also Hendricks et al. [6] and Schiedt et al. [7] on these dipole bound states in U,T and C) and in case of $\mathrm{U}$ and they were able to detect besides the dipole bound anion $\mathrm{U}^{-}$(with an electron affinity of $85 \mathrm{meV}$ ) also traces of the (U-H) fragment negative ion produced by stray free electrons present in their apparatus. They also observed valence bound $\mathrm{U}^{-}$(with an electron affinity of $70 \mathrm{meV}$ ), however only in the case when starting from a uracil/argon cluster thereby allowing to stabilize the uracil parent anion via evaporation of an argon atom (see also a recent paper by Hendricks et al. [8] reporting dipole bound to covalent transformation of the uracil anion when going from the gas phase situation to the condensed phase). On the other hand Huels et al. [9] studied formation of the negative ions produced by the interaction of free electrons with $\mathrm{T}$ and Cytosine $(\mathrm{C})$ molecules in a crossed electron-molecule beams experiment. They identified as major products at low electron energies the parent negative ions $\mathrm{T}^{-}$and $\mathrm{C}^{-}$.

In the present experimental study we investigated attachment of free electrons to $U, T$ and $\mathrm{C}$ in a crossed electron/molecule beams apparatus (using a set-up similar to the apparatus used by Huels et al. [9] though with a better energy and mass resolution) in order to follow up these earlier studies and thus to clarify the existing discrepancies in terms of the major reaction products in EA reactions. As will be demonstrated below according to the present study the major anions produced are $(\mathrm{U}-\mathrm{H})^{-},(\mathrm{T}-\mathrm{H})^{-}$and $(\mathrm{C}-\mathrm{H})^{-}$for EA to $\mathrm{U}, \mathrm{T}$ and $\mathrm{C}$, respectively, with no trace of any parent anion. This obviously has important implications concerning the mechanism of radiation damage.

\section{Experimental}

The present experiments were carried out with a crossed electron/molecule beams apparatus (Fig. 1) described in detail in [10]. The electron beam was formed in a custom built hemispherical electron monochromator HEM with a maximum resolution of about $30 \mathrm{meV}$, for reasons of higher sensitivity the present measurements were, however, performed with an electron energy resolution of about $90-120 \mathrm{meV}$ and electron currents of 5-8 $\mathrm{nA}$. The molecular beam was produced in a molecular beam source consisting of a temperature regulated oven and a capillary. Uracil, thymine and cytosine exist under standard condition as a powder and the vapour pressure is too low for a gas phase experiment. A sufficient vapour 
pressure for the formation of a molecular beam can be achieved at temperatures of about 450 $\mathrm{K}$. The molecular beam was formed by effusing the sublimated molecules through a capillary (diameter of about $0.8 \mathrm{~mm}$ ) into the reaction chamber. The electron beam is perpendicular crossing the molecular beam in the reaction chamber. The negative ions formed in the reaction chamber were extracted by a weak electric field (at maximum $200 \mathrm{meV} / \mathrm{cm}$ ) towards the entrance of the high resolution quadrupole mass spectrometer (QMS) with a mass range of up to $2000 \mathrm{amu}$. The mass selected negative ions were detected by a channeltron detector and the pulses processed using a pulse counting technique and computer. The intensity of a mass selected negative ion was recorded as a function of the electron acceleration voltage.

The electron energy scale was calibrated using the electron attachment (EA) reaction

$\mathrm{CCl}_{4}+\mathrm{e} \rightarrow \mathrm{Cl}^{-}+\mathrm{CCl}_{3}$

which has a narrow s-wave resonance at $0 \mathrm{eV}$. The apparent width of the resonance was used as a measure for the electron energy resolution of the electron beam and its position to define the zero energy point of the energy scale.

In the present experiment we have also obtained a measure for the partial cross section for EA to $\mathrm{U}, \mathrm{T}$ and $\mathrm{C}$. This was done by comparison of the nucleic base fragment ion currents obtained for the various EA reactions with the ion current from reaction (1) at the 0.8 resonance. If reaction (1) is measured under identical conditions as the electron attachment reactions to the bases (i.e., identical pressure as read on the ionization gauge in the main chamber and identical electron current), then an estimate for the absolute partial cross sections for the various reactions can be obtained from the measured ion current ratios and the known absolute partial cross section for reaction (1) of $\left(5 \times 10^{-20} \mathrm{~m}^{2}\right)$ [11] (for more details on the accuracy of this method taking also into account discrimination due to kinetic energy release in the dissociation reaction see discussion in [12]).

It is quite important to add here a note of caution when using $\mathrm{CCl}_{4}$ (or as sometimes is the case $\mathrm{SF}_{6}$ ) as calibration gas (see above) simultaneously in the molecular target beam as the gas under investigation. As found out in the present study already minute amounts of calibration gas may lead to a contaminant ion signal at about zero eV electron energies which is masking a small peak at about $40 \mathrm{meV}$ for the $(\mathrm{X}-\mathrm{H})^{-}$anions with $\mathrm{X}=\mathrm{U}, \mathrm{T}$ and $\mathrm{C}$. Fig 2 shows as an example an apparent $(\mathrm{T}-\mathrm{H})^{-}$anion signals versus electron energy at two different $\mathrm{SF}_{6}$ admixtures, ranging from a nominal partial $\mathrm{SF}_{6}$ gas pressure (as read on the ion gauge in the main chamber which certainly is giving lower values than the ones present at the interaction region) of about $6.5 \times 10^{-8}$ Torr (upper panel) to a situation with no calibration gas at all (lower panel). It can be seen that for measurements without the presence of a calibration gas a small peak at about $40 \mathrm{meV}$ is present, whereas admixture of the calibration gas leads to an additional peak at about zero eV electron energy. This additional peak at zero eV is directly proportional to the amount of gas admixture (for more details see Fig.3 in [13] showing the dependence of this artefact peak versus calibration anion signal for $\mathrm{CCl}_{4}$ and $\mathrm{SF}_{6}$ ). Additional mass spectrometric investigations have lead us to the conclusion that this zero $\mathrm{eV}$ artefact peak is due to the production of anions from the calibration gas (in case of both calibration gases anions are produced very effectively at zero eV electron energy) and subsequent ion molecule reactions with the gas under investigations, one typically reaction sequence being

$\mathrm{CCl}_{4}+\mathrm{e} \rightarrow \mathrm{Cl}^{-}$and $\mathrm{Cl}^{-}+\mathrm{T} \rightarrow(\mathrm{T}-\mathrm{H})^{-}+\mathrm{HCl}$

Similar observations have been made for cytosine and also uracil. 


\section{Results}

The electron attachment reactions to the RNA base $\mathrm{U}$ and the DNA bases T and C may result in the formation of a large variety of negative ions and neutral products $[9,14]$. The aim of the present study was the unambiguous identification of the most abundant negative ions, i.e. whether this is $\mathrm{X}^{-}$as discussed in [9] or $(\mathrm{X}-\mathrm{H})^{-}$as recently reported in [14]). Many fragment negative ions were observed. In order to identify the negative ions, we have performed a very thorough mass calibration based on isotopic analysis of the mass spectra, as the differences in the mass to charge ratio of the corresponding ions of interest here $\left(\mathrm{U}^{-}\right.$and $(\mathrm{U}-\mathrm{H})^{-}, \mathrm{T}^{-}$and $(\mathrm{T}-\mathrm{H})^{-}$, and $\mathrm{C}^{-}$and $\left.(\mathrm{C}-\mathrm{H})^{-}\right)$are very small. According to the present analysis the most abundant negative ions formed via EA to $\mathrm{U}, \mathrm{T}$ and $\mathrm{C}$ are $(\mathrm{U}-\mathrm{H})^{-}$(mass to charge ratio (MCR) 111), (T-H) ${ }^{-}$(mass to charge ratio (MCR) 125) and (C-H) ${ }^{-}$(MCR 110). Huels et al. [9] identified as the most abundant product ions of EA to $\mathrm{T}$ and $\mathrm{C}$ the parent negative ions $\mathrm{T}^{-}$and $\mathrm{C}^{-}$, respectively, with no mention of the presence of either $(\mathrm{T}-\mathrm{H})^{-}$and $(\mathrm{C}-\mathrm{H})^{-}$anions. The present identification is also supported by the fact that Schermann and co-workers [5] observed in their Rydberg transfer studies (leading to weakly bond dipole-bound parent anions) traces of $(\mathrm{U}-\mathrm{H})^{-}$and $(\mathrm{T}-\mathrm{H})^{-}$produced by stray electrons.

Moreover, in the present experiment the parent negative ions $\mathrm{U}^{-}, \mathrm{T}^{-}$and $\mathrm{C}^{-}$could not be observed at all, neither could be seen the respective anion dimer signals (the latter indicating also the absence of appreciable amounts of neutral dimers present in the beam). Although we have detected a weak negative ion yield at the MCR corresponding to the parent negative ions, i. e.,MCR 112 for $\mathrm{U}^{-}, \mathrm{MCR} 126$ for $\mathrm{T}^{-}$and MCR 111 for $\mathrm{C}^{-}$, the measured ion yield curves (ion yield versus electron energy) show the same shape as the fragment negative ions $(\mathrm{U}-\mathrm{H})^{-}$at $\mathrm{MCR}$ 111, (T-H) ${ }^{-}$at $\mathrm{MCR} 125$ and $(\mathrm{C}-\mathrm{H})^{-}$at MCR 110, respectively. Nevertheless these ion yields are much weaker than that for the $(\mathrm{U}-\mathrm{H})^{-},(\mathrm{T}-\mathrm{H})^{-}$and $(\mathrm{C}-\mathrm{H})^{-}$ anions and the ratios between the ion yields at mass 111 and 112, 125 and 126 and 110 and 111 corresponds to the expected isotope ratio between the first and second isotopomer for the corresponding $(\mathrm{U}-\mathrm{H})^{-},(\mathrm{T}-\mathrm{H})^{-}$and $(\mathrm{C}-\mathrm{H})^{-}$ions. Thus we have to conclude that no or only negligible amounts of parent ions $\mathrm{U}^{-}, \mathrm{T}^{-}$and $\mathrm{C}^{-}$are produced by free electron attachment.

The ion yield curves for the $(\mathrm{U}-\mathrm{H})^{-},(\mathrm{T}-\mathrm{H})^{-}$and $(\mathrm{C}-\mathrm{H})^{-}$negative ions formed via EA to the corresponding bases are shown in Fig. 3. The ion yield has been measured in the electron energy range from about 0 to $9 \mathrm{eV}$. We are able to recognise in the ion yield curve several resonances. The closed shell anion $(\mathrm{U}-\mathrm{H})^{-}$is produced mainly at energies below about $5 \mathrm{eV}$. By a comparing anion currents measured under defined pressure conditions in the target region and using the accurately known DEA cross section in $\mathrm{CCl}_{4}$ at $0.8 \mathrm{eV}$ we can estimate the DEA cross section in uracil leading to hydrogen radical abstraction to have a value of $\approx 3 \times 10^{-20} \mathrm{~m}^{2}$ at the peak maximum. The resonances in the shape of the $(\mathrm{U}-\mathrm{H})^{-}$cross section curve indicate that it is formed by resonant dissociative electron attachment (DEA) where $\mathrm{U}^{\#-}$ is the transient negative ion generated by the initial Franck-Condon transition. DEA is in fact the only mechanism to induce a bond cleavage at such low electron energies. The ion yield curve indicates that presumably different negative ion states of the precursor ion $U^{\#-}$ are involved (for more details see a recent report [14]). At higher electron energies, in the range between about $3-12 \mathrm{eV}$ we observe further products $\left(\mathrm{CN}^{-}, \mathrm{OCN}^{-}\right.$and $\left.\mathrm{C}_{3} \mathrm{OH}_{2} \mathrm{~N}^{-}\right)$, however, at significant lower cross sections. These smaller product anions arise from complex decomposition processes involving cleavage of the aromatic ring. Fig.4 shows as an example the cross section for the formation of $\mathrm{OCN}^{-}$and $\mathrm{C}_{3} \mathrm{H}_{2} \mathrm{NO}^{-}$exhibiting resonances at similar peak positions (albeit with different relative magnitudes) indicating that these ions may be originating from the same negative ion states of the precursor ion $U^{\#-}$.

The dominant $(\mathrm{T}-\mathrm{H})^{-}$resonance is at $1.05 \mathrm{eV}$, followed by a resonances at 1.48 and a broad resonance at $1.75 \mathrm{eV}$. The formation of the $(\mathrm{T}-\mathrm{H})^{-}$negative ion was observed also slightly above about $0 \mathrm{eV}$, at $0.74 \mathrm{eV}$ and at higher electron energies $(5.5,6.7$ and $7.8 \mathrm{eV})$. 
The shape of the (T-H) ${ }^{-}$ion yield resembles the (U-H) ${ }^{-}$ion yield formed via EA to U reported in our recent study (see [14]] and shown for comparison also in Fig.3. In the case of EA to U, according to ab initio calculations, some of the low electron energy resonances correspond to dissociation of $\mathrm{H}$ atoms from particular positions on the $\mathrm{U}$ molecule and thus formation of $(\mathrm{U}-\mathrm{H})^{-}$negative ions with different geometric and electronic structures $\left((\mathrm{U}-\mathrm{H})^{-}\right.$isomers). We assume that in case of the (T-H) $)^{-}$ion some of the low electron energy resonances are due to similar reactions. The cross section for formation of $(\mathrm{T}-\mathrm{H})^{-}$from $\mathrm{T}$ at $1.05 \mathrm{eV}$ has a value of $1.2 \times 10^{-19} \mathrm{~m}^{2}$. This cross section is thus about 3 times larger than the cross section for (U-H) $/ \mathrm{U}$ reported in [9].

It is interesting to note that the present ion yield curve for formation of $(\mathrm{T}-\mathrm{H})^{-}$is very different to the $\mathrm{T}^{-}$curve reported in [9]. In contrast to the present observation Huels et al. [9] observed for $\mathrm{T}^{-}$a strong and broad resonance at around zero electron energy. Many resonances observed in our spectrum are not present in the $\mathrm{T}^{-}$spectrum of [9] and vice versa. Thus there exist obvious differences between the present $(\mathrm{T}-\mathrm{H})^{-}$and $\mathrm{T}^{-}$ion yield from [9]. It may be important to note in this context that Huels et al. [9] used an admixture of $\mathrm{SF}_{6}$ gas for calibration of the electron energy scale via the cross section curve $\mathrm{SF}_{6}{ }^{-} / \mathrm{SF}_{6}$. Electron attachment to $\mathrm{SF}_{6}$ has at elevated gas temperatures an effective dissociative attachment channel resulting in the formation of $\mathrm{SF}_{5}{ }^{-}$ion (MCR 127). If the mass resolution of the mass spectrometer in [9] was not sufficient, it is therefore perceivable that the apparent $\mathrm{T}^{-}$ion yield (MCR 126) may be due to the $\mathrm{SF}_{5}{ }^{-}$ion yield contaminating the MCR 127. This interpretation is supported by the fact, that the $\mathrm{T}^{-}$ion yield curve resembles in the low electron energy range the ion yield curve of the $\mathrm{SF}_{5}{ }^{-} / \mathrm{SF}_{6}$ channel (e.g., see the results in [15]).

The ion yield for formation of $(\mathrm{C}-\mathrm{H})^{-}$via EA to $\mathrm{C}$ is also shown in Fig. 3. The $(\mathrm{C}-\mathrm{H})^{-}$ ion yield was measured in the electron energy range from 0 to $9 \mathrm{eV}$. The $(\mathrm{C}-\mathrm{H})^{-}$ion has the strongest resonance at $1.54 \mathrm{eV}$ and additional weak resonances at slightly above $0,5.2$ and 6.7 $\mathrm{eV}$. The shape of the present $(\mathrm{C}-\mathrm{H})^{-}$ion yield curve is very similar to the $\mathrm{C}^{-}$ion yield curve reported in [9]. This is indicative that in fact Huels et al. [9] also observed $(\mathrm{C}-\mathrm{H})^{-}$negative ion, but due to a lower mass resolution of their mass spectrometer (see also above) the ion was identified as $\mathrm{C}^{-}$. The presently determined cross section for the formation of $(\mathrm{C}-\mathrm{H})^{-}$via EA to $\mathrm{C}$ has a value of $2.3 \times 10^{-20} \mathrm{~m}^{2}$ and is thus about a factor of 5 lower than the cross section for $\mathrm{T}$ and thus rather similar to that of $(\mathrm{U}-\mathrm{H})^{-} / \mathrm{U}$ reported in $[14]$ with about $3 \times 10^{-20} \mathrm{~m}^{2}$.

In conclusion, free electron attachment to thymine and cytosine proceeds in a similar manner as in the case of uracil, i.e., yielding on the one hand no parent anions at all, and on the other hand as the major fragment anion the $(\mathrm{X}-\mathrm{H})^{-}$with $\mathrm{X}=\mathrm{U}, \mathrm{T}$, or $\mathrm{C}$. This similar behaviour is in accordance with the fact that known dipole bound electron affinities, valence bound electron affinities and vertical electron affinities are quite similar for these compounds. See also a recent theoretical study indicating that the covalent uracil and thymine are bound, while adenine is unbound and for cytosine the adiabatic electron affinity oscillates between small positive and negative values for the three most reliable functional combinations used for the calculations [16].

\section{Acknowledgment}

Work partially supported by FWF and ÖNB, Wien, Austria and the EU Commission, Brussels.

\section{Figure captions}

Fig.1 Schematic of the experimental setup 
Fig. 2 (T-H) ${ }^{-}$ion signal versus electron energy for two different admixtures (as read on the ionization gauge in the main chamber) of the calibrant gas, upper panel: $6.5 \times 10^{-8}$ Torr, lower panel: no calibrant gas present.

Fig. 3 The cross section for the formation of $(\mathrm{U}-\mathrm{H})^{-}$ion via EA to uracil (designated by dotted line) of (T-H) ${ }^{-}$ion via EA to thymine (designated by full line and multiplied by 0.33 ) and of $(\mathrm{C}-\mathrm{H})^{-}$ion via EA reaction to cytosine (designated by dashed line).

Fig. 4 The cross section for the formation of $\mathrm{OCN}^{-}$(designated by dashed line) and $\mathrm{C}_{3} \mathrm{H}_{2} \mathrm{NO}^{-}$ (designated by dotted line) ion via EA to uracil.

\section{References}

[1] B. D. Michael and P. A. O'Neill. Science 287, 1603 (2000).

[2] V. Cobut, Y. Fongillo, J. P. Patau, T. Goulet, M.-J. Fraser, and J.-P. Jay-Gerin, Radiat. Phys. Chem. 51, 229 (1998), and references cited therein.

[3] 1. International Commission on Radiation Units and Measurements, ICRU Report 31 (ICRU, Washington, DC, 1979)

[4] B. Boudaiffa, P. Cloutier, D. Hunting, M. A. Huels and L. Sanche, Science, 287, 1658 (2000).

[5] C.Desfrancois, H.Abdoul-Carime and J.P.Schermann, J.Chem.Phys., 104, 7792 (1996) and references therein.

[6] J.H.Hendricks, S.A.Lyapustina, H.L.de Clercq, J.T.Snodgrass and K.H.Bowen, J.Chem.Phys., 104, 7788 (1996)

[7] J.Schiedt, R.Weinkauf, D.M.Neumark and E.W.Schlag, Chem.Phys., 239, 511 (1998)

[8] J.H.Hendricks, S.A. Lyapustina, H.L.de Clercq and K.H.Bowen, J.Chem.Phys., 108, 8 (1998)

[9] M. A. Huels, I. Hahndorf, E. Illenberger, and L. Sanche J. Chem. Phys. 108, 1309 (1998).

[10] D. Muigg, G. Denifl, A. Stamatovic, T.D. Märk, Chem. Phys., 239, 409 (1998).

[11] S.C. Chu and P.D. Burrow, Chem. Phys. Lett. 172, 17 (1990) .

[12] P.Cicman, M.Francis, J.D.Skalny and T.D.Märk, Int.J.Mass Spectr., 223/224, 271 (2003) and references therein.

[13] S.Denifl, S.Ptasinska, M.Cingl, S.Matejcik, P.Scheier and T.D.Märk, Chem.Phys.Letters, in print (2003)

[14] G. Hanel, B. Gstir, P. Scheier, M. Probst, B. Farizon, M. Farizon, E. Illenberger and T. D. Märk, Phys. Rev. Lett., 90, 188104 (2003)

[15] L.G.Christophorou, D.L.McCorkle and A.A.Christodoulides, Chapter3 in ElectronMolecule Interactions and their Applications, Vol.1, L.G.Christophorou, Academic Press, Orlando 1984.

[16] S.S.Wesolowski, M.L.Leininger, P.N.Pentchev and H.F.Schaefer III, J.Am.Chem.Soc., 123, 4023 (2001) 


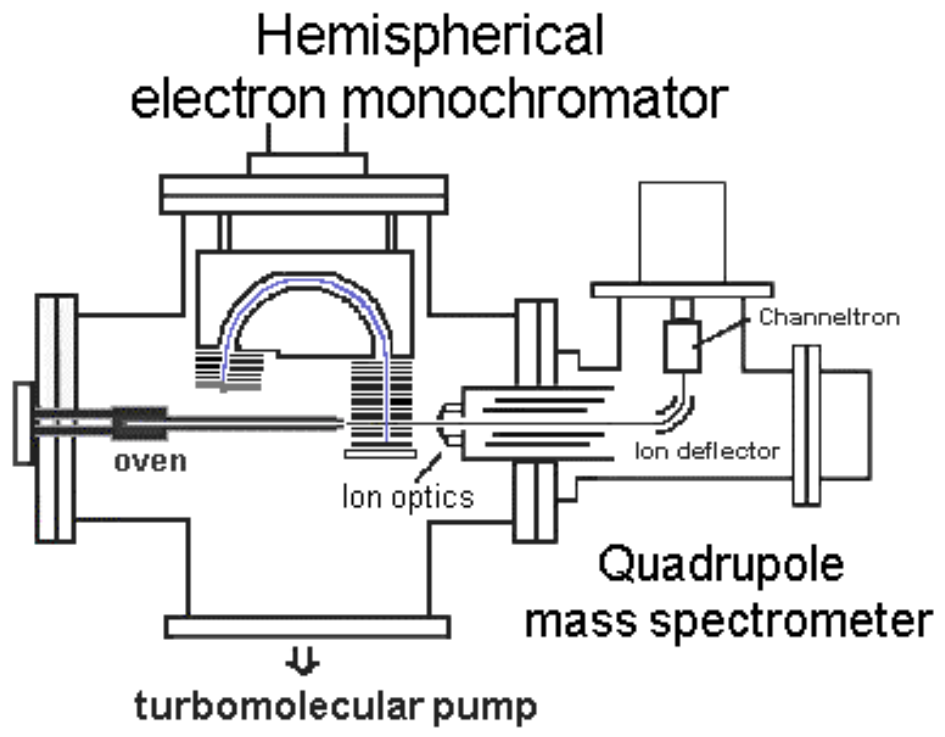

Fig. 1

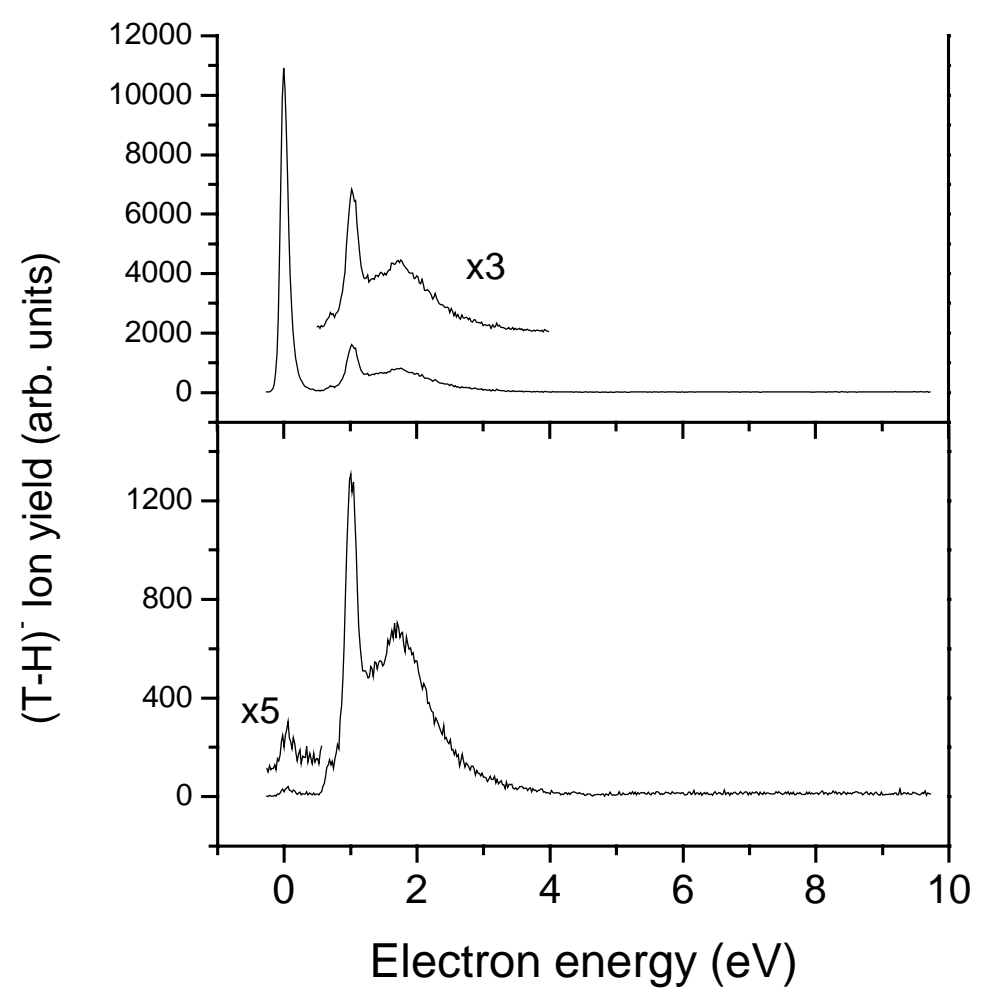

Fig. 2 


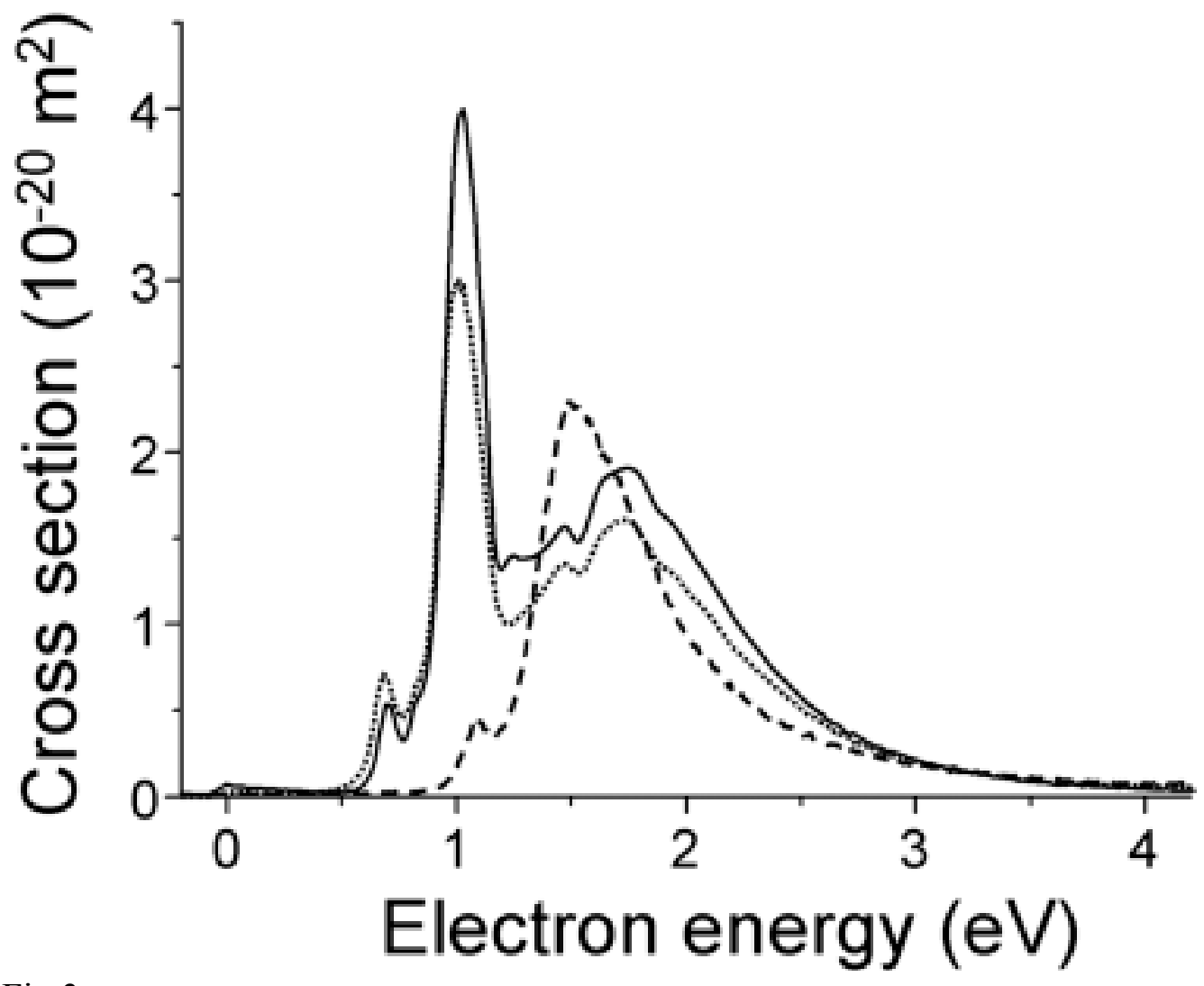

Fig. 3

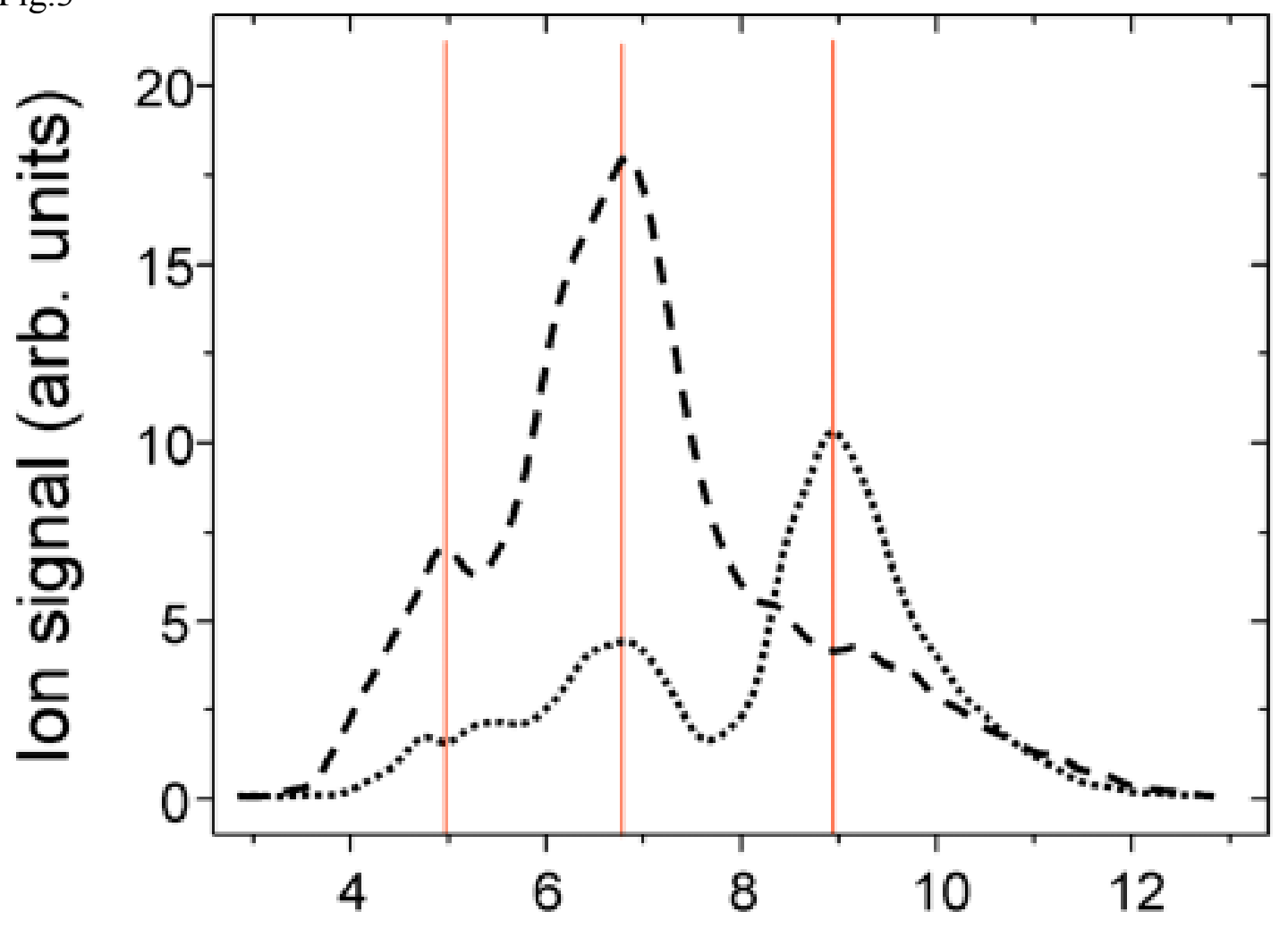

Electron energy (eV)

Fig.4 